\title{
Intestinal hypersecretion of the refed starved rat: a model for alimentary diarrhoea
}

\author{
A Young ${ }^{\star}, \mathrm{R} J$ Levin
}

\begin{abstract}
Fluid transport was gravimetrically measured in vivo in the duodenum, jejunum, and ileum of anaesthetised fed, 72 hour starved and 72 hour starved rats refed for up to five days after starvation. Basal unstimulated fluid transport was monitored by instilling $0.9 \% \mathrm{NaCl}$ into the lumen and measuring the gain or loss in weight of the closed intestinal loop. Fluid was absorbed in all the areas of the intestine in the fed rats. Increasing basal fluid absorption was observed in the duodenum over the three days of starvation but in the jejunum there was no significant change. In the ileum, the pattern was very different, on day 1 the fluid was absorbed but on days 2 and 3 there was an increasing secretion of fluid. Refeeding the rats with their normal diet restored the basal absorption of fluid in the duodenum within 24 hours, had no effect in the jejunum but in the case of the ileum the hypersecretion of fluid observed in the day 3 starved rat was maintained on day 1 of refeeding, increased further on day 2, decreased on day 3 but returned to absorption on day 4. The normal absorption was restored to the ileum on day 5 of refeeding. Fluid secretion was induced in all the rat groups by bethanechol (ip $60 \mu \mathrm{g} / \mathrm{kg} \mathrm{bw}$ ) a stable cholinergic agonist, PGE $_{2}$ (ip $10 \mu \mathrm{g} / \mathrm{kg}$ (bw) and $E$ coli STa (luminally insilled, $500 \mathrm{ng} /$ $\mathrm{ml}$ ) a secretory enterotoxin. All the secretagogues gave enhanced secretion compared with the fed by day 2 of starvation which increased considerably on day 3 . Refeeding returned their secretion back to the fed level in the duodenum within 24 hours, in the jejunum within $\mathbf{4 8}$ hours but in the ileum their induced secretion on day 2 of refeeding was greater than that of the day 3 starved and took until day 4 to return to the fed levels for behanechol and $\mathrm{PGE}_{2}$ and until day 5 for $E$ coli STa. This behaviour of rat small intestine showing even greater hypersecretion in the refed state than the starved mimics the human condition of alimentary induced diarrhoea where incautious feeding of starved humans induces severe, often lethal diarrhoea. The refed starved rat appears to be a possible model for this condition.

(Gut 1992; 33: 1050-1056)
\end{abstract}

Diarrhoea is a common occurrence in severely starved or undernourished man. ${ }^{12}$ Incautious refeeding exacerbates the diarrhoea so that, a few days after realimentation, death may occur. ${ }^{1-6}$ The most detailed study of this phenomenon was by Helweg-Larsen et al, ${ }^{\prime}$ concerning severely malnourished Danish subjects who had been incarcerated in a second world war concentration camp. They described a non-febrile, 'hunger diarrhoea' that was exacerbated if the victims were allowed unrestricted access to food: treatment with opiates appeared to be of little value. Only a slow, cautious, increase in food intake helped, but most subjects died from the realimentation. This type of diarrhoea was designated as 'alimentary or dietary' diarrhoea. Descriptive experimental studies by Thaysen and Thaysen ${ }^{7}$ using a limited number of young, starved rats revealed that refeeding their ordinary diet caused a number to die within a few days, often showing frank diarrhoea. If, however, concentrated skimmed milk and glucose were fed, death was prevented and the rats regained their normal weight after seven to 10 days. The explanation for the exacerbation of the diarrhoea by the refeeding was that it was the result of overloading the putatively reduced absorptive capacity of the small and large bowel. More recently, Roediger, ${ }^{28}$ focusing on the absorptive functions of the intestine, suggested that the luminal nutrition of the enterocytes and especially of the colonocytes by fatty acids, is essential for their normal absorptive function to be manifest. Lack of such luminal nutrition in starvation supposedly reduces the absorptive/ digestive capacity of the gut so that when a sudden nutrient load is presented to the energy deprived mucosal cells they fail to function efficiently and the unabsorbed nutrient load, by its osmotic action, pulls fluid into the gut lumen (creating an osmotic diarrhoea). Contrary to the hypothesis, however, nutrient absorption from the small intestine in the starved rat often has been reported as being increased rather than reduced. ${ }^{9}$

Over the last few years, we have shown that after 24 hours, progressive starvation of up to three days duration induces hypersecretion in the rat small intestine, ${ }^{10-12}$ large intestine,${ }^{13}$ and also the rectum ${ }^{14}$ in response to a variety of secretagogues and bacterial toxins. ${ }^{15}$ The starved rat thus appears to be a useful model for studying the hunger or famine diarrhoea observed in humans. ${ }^{17}$ In order to assess the utility of the rat as a model for 'alimentary diarrhoea' the effects of refeeding the starved rat were examined using electrogenic $\mathrm{Cl}^{-}$secretion, measured as the short circuit current (Isc), across duodenal, jejunal and ileal sheets of intestine in vitro. ${ }^{16}$ All segments developed increasing hypersecretory activity to secretagogue stimulation between 24 72 hours of starvation. After $24-48$ hours of refeeding, however, although the activity of the duodenum and jejunum returned to the fed level, that of the ileum remained at the high starved level for the first 24 hours of refeeding and was then increased even further after 48 hours of refeeding. It did not return to fed levels 
until 96 hours of refeeding. A similar behaviour pattern was noted for the starved proximal colon's electrogenic secretory response to refeeding. ${ }^{17}$ While the adult, conscious rat does not usually show overt diarrhoea this is because of its huge caecal reserve capacity. ${ }^{18}$ The underlying secretory behaviour of the fed/starved rat namely, the 'alimentary induced intestinal hypersecretion' mimics certain aspects of the human condition of 'alimentary diarrhoea.' The model offers a useful preparation to examine the mechanisms that generate the condition.

The present study characterises, in vivo, the fluid absorptive and secretory behaviour of the duodenum, jejunum, and ileum in starved and refed rats in the basal condition and after stimulation with either bethanechol (a stable cholinomimetic), $\mathrm{PGE}_{2}$ (a prostaglandin agonist) or $E$ coli STa (a bacterial enterotoxin). These secretagogues were chosen because they utilise, respectively, the three major intracellular second messengers that activate secretion in the enterocytes - namely, $\mathrm{Ca}^{++}$, cyclic AMP, and cyclic GMP. In general, apart from a few minor differences, the fluid movements measured in vivo match the previously recorded electrogenic secretory responses obtained in vitro..$^{10-1216}$

\section{Methods}

ANIMALS AND DIETARY STATUS

Albino male rats of the Sheffield (Wistar) strain (wt range 230-260 g) were housed in plastic cages with raised, wire mesh bottoms to minimise coprophagy. The temperature $\left(20^{\circ}\right.$ (1)C), humidity (78\%) and lights (on from 530 am to $630 \mathrm{pm}$ ) were controlled. All animals were allowed free access to drinking water. Those fed the control diet were allowed free access to the pelleted food (Diet CRM, Labsure, Cambridge, England). Various groups of rats were starved for 24,48 , and 72 hours with free access to water. Realimentation of the 72 hour starved rats was accomplished by allowing the rats free access to the pelleted food for $24,48,72,96$, and 120 hours after the starvation period.

\section{MEASUREMENT OF FLUID SECRETION/ABSORPTION} IN VIVO

On the day of use, the rats were anaesthetised with ip sodium pentobarbitone (Sagatal, May \& Baker, $60 \mathrm{mg} / \mathrm{kg}$ bwt). Fluid transport was measured in isolated, tied off loops of proximal duodenum $(8 \mathrm{~cm})$, midjejunum $(20-30 \mathrm{~cm})$, and proximal ileum $(15-20 \mathrm{~cm})$ as described previously. ${ }^{10}$ In brief, after attainment of surgical anaesthesia, a midline abdominal incision was made and the appropriate section of intestine located and cannulated proximally. The segment was washed with prewarmed $0.9 \% \mathrm{NaCl}$ to flush out luminal debris and then gently blown through to remove excess residual fluid, care being taken to avoid any distention. The distal end of the loop was closed with a ligature and $0.3-0.6 \mathrm{ml}$ of prewarmed $0.9 \% \mathrm{NaCl}$ was injected into the loop from a preweighed syringe. The fluid injected was obtained by reweighing the syringe. The proximal end of the loop was then closed with a ligature and a secretagogue was administered intraperitoneally or in the case of $E$ coli STa into the lumen. The secretagogues were bethanechol $(60 \mu \mathrm{g} / \mathrm{kg}$ bwt $), \mathrm{PGE}_{2}(10 \mu \mathrm{g} /$ $\mathrm{kg}$ bwt), and $E$ coli STa $(500 \mathrm{ng} / \mathrm{ml})$. Control experiments were undertaken using a similar volume of $0.9 \% \mathrm{NaCl}$ instead of the secretagogue to monitor basal secretion and absorption in the unstimulated rat. The abdomen was closed with a clamp and covered with a warm, $0.9 \% \mathrm{NaCl}$ soaked swab. The rats were left for periods of up to 30 minutes on a heated table, their body temperatures were monitored by rectal thermometers. At the end of the period, the rats were killed by thoracic incision. The intestinal loops were cut from the animal close to the ligatures, dissected free from mesentery and their length measured. They were quickly blotted free of blood and weighed. The loop was cut open and the remaining fluid drained. The cut ends were blotted to remove adherent fluid and the cut, empty loops reweighed. The volume gained (=secretion, designated as positive) or lost (=absorption, designated as negative) could be determined from the various weighings of the fluid and the isolated loop. The results were expressed on a length basis $(\mu \mathrm{g}$ fluid $/ \mathrm{cm}$ intestine/minute). All drugs and chemicals were obtained from the Sigma Chemical Company, England, except for $\mathrm{PGE}_{2}$ which was purchased from Upjohn Company, Crawley, Surrey, England. Results are given as the mean (1 SEM) with the number of rats used in square brackets.

\section{STATISTICAL ANALYSIS}

Multiple comparisons of the data were accomplished first by the Kruskal-Wallis nonparametric analysis of variance followed by Conover's multiple $t$ test to identify specific significant differences using the computer program of Theodorsson-Nordheim. ${ }^{19}$ Statistical significance was assumed when $\mathrm{p} \leq 0.05$.

\section{Results}

DAILY FOOD INTAKES

The daily food intakes of rats refed after three days starvation was monitored to ensure that they consumed a level commensurate with that of normal fed controls. The results are shown in Table I. None of the food intakes on the refeeding days were significantly different from those of the fed controls.

FLUID MOVEMENTS DURING STARVATION AND REFEEDING

\section{Basal fluid movements}

The results for the net fluid transport into (secretion) and from (absorption) the lumen of the proximal duodenum, midjejunum and proximal ileum for the basal, unstimulated condition in fed control, starved and refed starved rats are shown in Table II. In the case of the duodenum a significant increase in the net basal absorption was not seen until day 2 of starvation $(+30 \%$, a $v \mathrm{c}, \mathrm{p}<0.01)$. There was a small, 
TABLE I Daily food intake per rat in $g$ for fed controls and rats starved for three days and then refed for $1,2,3,4$, and 5 days. Results are shown as mean (SE) with number of animals used in square brackets

\begin{tabular}{ll}
\hline & Daily food intake $(\mathrm{g})$ \\
\hline Fed control & $24(2)[7]$ \\
Starved and 1 day refed & $28(2)[10]$ \\
Starved and 2 day refed & $26(1)[12]$ \\
Starved and 3 day refed & $26(2)[9]$ \\
Starved and 4 day refed & $25(1)[8]$ \\
Starved and 5 day refed & $25(2)[8]$ \\
\hline
\end{tabular}

TABLE II Net basal fluid movement in proximal duodenum, jejunum, and ileum of fed, day 1 to day 3 starved and day 1 to day 5 refed rat. Results are shown as the mean $(S E)$ with the number of animals used in square brackets

\begin{tabular}{llll}
\hline \multicolumn{4}{c}{$\mu g$ Fluid/min/cm } \\
\cline { 2 - 4 } & Duodenum & fejunum & Ileum \\
\hline Fed & $-573(36)[7]^{\mathrm{a}}$ & $-799(41)[6]^{\mathrm{g}}$ & $-717(36)[6]^{\mathrm{n}}$ \\
Starved day 1 & $-601(43)[6]^{\mathrm{b}}$ & $-836(36)[6]^{\mathrm{h}}$ & $-693(31)[6]^{\mathrm{o}}$ \\
Starved day 2 & $-747(31)[7]^{\mathrm{c}}$ & $-811(31)[7]^{\mathrm{i}}$ & $+109(43)[6]^{\mathrm{p}}$ \\
Starved day 3 & $-804(43)[6]^{\mathrm{d}}$ & $-741(43)[7]^{\mathrm{j}}$ & $+596(49)[6]^{\mathrm{g}}$ \\
Day 1 refed & $-617(37)[6]^{\mathrm{c}}$ & $-737(29)[9]^{\mathrm{k}}$ & $+639(41)[6]^{\mathrm{j}}$ \\
Day 2 refed & $-549(51)[6]^{\mathrm{f}}$ & $-803(43)[6]^{\mathrm{j}}$ & $+979(37)[7]^{\mathrm{s}}$ \\
Day 3 refed & - & $-819(37)[6]^{\mathrm{m}}$ & $+373(47)[6]^{\mathrm{t}}$ \\
Day 4 refed & - & - & $-223(31)[6]^{\mathrm{u}}$ \\
Day 5 refed & - & - & $-699(31)[7]^{\mathrm{v}}$ \\
\hline
\end{tabular}

Net secretion (fluid movement to lumen) is given as positive while net absorption (fluid loss from lumen) is given as negative. The fluid movements were measured over 20 minute period but calculated per unit time. Statistical comparisons used the KruskalWallis analysis of variance (ANOVA) with specific differences delineated by Conover's multiple $t$ test (see text).

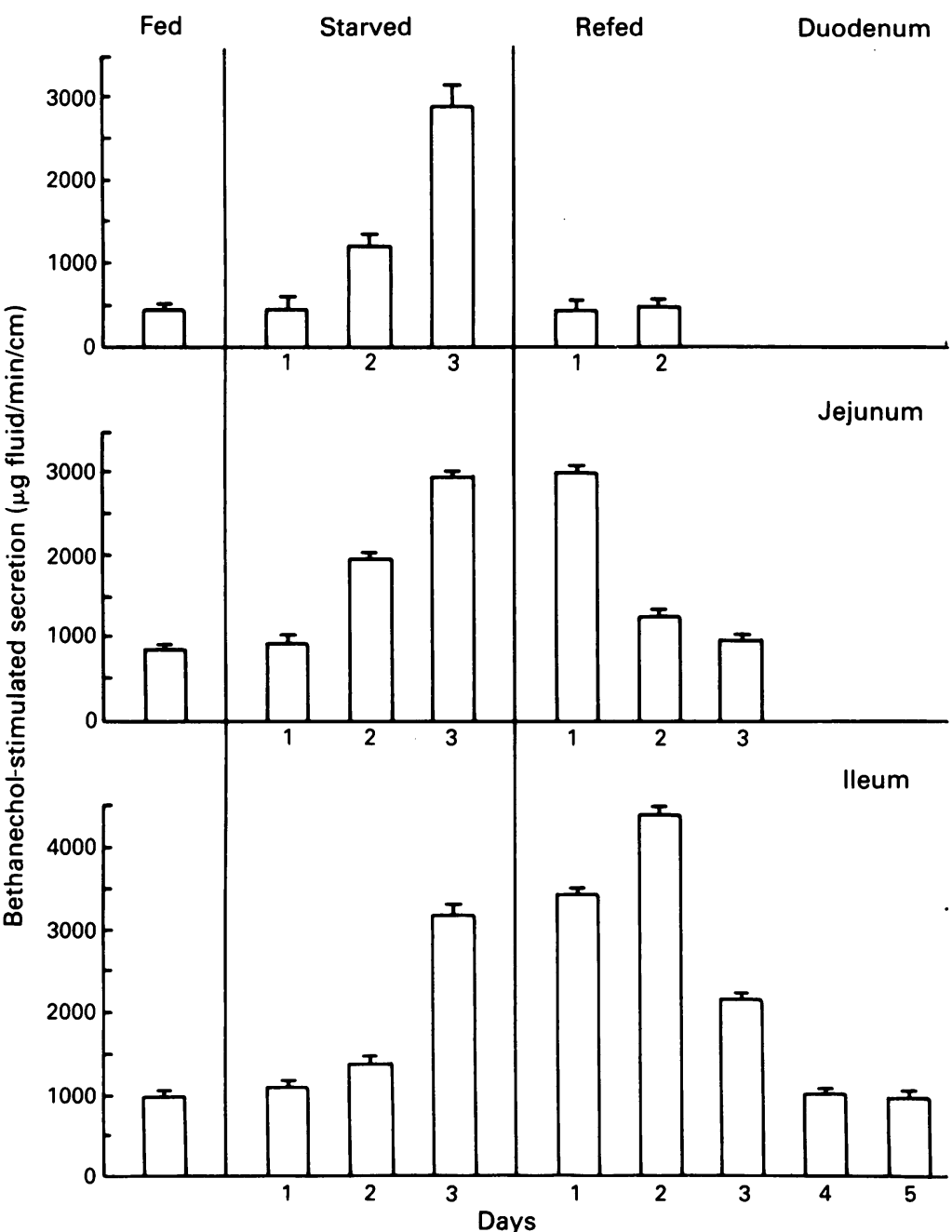

Figure 1: Bethanechol stimulated fluid secretion $(\mu \mathrm{g}$ fluid/min/cm) in the duodenum, jejunum, and ileum of fed, 72 hour starved and refed 72 hour starved rats. The results are plotted as mean (SE). The number of animals used varied between six and 13. Bethanechol was given ip at a dose of $60 \mu \mathrm{g} / \mathrm{kg}$ bwt. See text for details of statistical significance of comparisons by Conover's multiple $\mathrm{t}$ test. further significant increase in the absorption on day 3 of starvation $(+7 \cdot 6 \%$, c $v \mathrm{~d}, \mathrm{p}<0 \cdot 01)$. Allowing access to food for one day (day 1 refed), after the three day starvation, restored the basal absorption to the fed control level and a second day of feeding (day 2) had no further effect. The jejunal basal absorption showed no significant change during the three days of starvation or by the refeeding compared with the fed controls.

The behaviour of the basal activity of the proximal ileum to. starvation showed some surprising differences from either that of the duodenum or jejunum. The first day of starvation (day 1) caused a small but insignificant reduction of the basal absorption. On the second day (day 2) the net absorptive tone was converted to a net secretory one ( $\mathrm{n} v \mathrm{p}, \mathrm{p}<0.001)$ and this secretory tone was greatly increased by day $3(+447 \%$, $\mathrm{p} v \mathrm{q}, \mathrm{p}<0.001)$. One day after refeeding, there was an insignificant increase in the basal secretion compared with day 3 of starvation $(+7 \%$, $\mathrm{q} v \mathrm{r}, \mathrm{p}>0.05$ ), but on the second day of refeeding the basal secretion was enhanced further compared with that on day 3 of starvation $(+64 \%, q v s, p<0 \cdot 001)$. The secretion then fell significantly on the third day of refeeding compared with previous day (day 2 refeeding) by $61.9 \%$ ( $\mathrm{s} v \mathrm{t}, \mathrm{p}<0.001$ ). On the fourth day of refeeding the net secretory tone was reversed to a net absorptive tone which was significantly smaller than that on day 5 of refeeding $(-68 \cdot 1 \%$, $\mathrm{u} v \mathrm{v}, \mathrm{p}<0.001)$ and the absorptive tone measured in the fed $(-68.9 \%, \mathrm{n} v \mathrm{u}, \mathrm{p}<0.001)$ or day 1 starved animals $(-67 \cdot 8 \%, o v \mathrm{u}, \mathrm{p}<0 \cdot 01)$. By the fifth day of refeeding, the absorptive tone was not significantly different to that of the fed or day 1 starved rats.

\section{Bethanechol stimulated fluid movements}

The changes induced in the net fluid secretion evoked by bethanechol are shown in Figure 1 . Compared with the fed, a significant increase in the duodenal secretion was not observed until the second day of starvation (day $2,+170 \%$, $\mathrm{p}<0.001$ ). This was greatly increased on the third day of starvation (day $3,+560 \%$, $\mathrm{p}<0.001$ ). Refeeding for one day restored the secretion to the level of the fed controls and the second day of refeeding (day 2) had no further effect.

In the jejunum, a significant increase in the bethanechol stimulated secretion was only observed after two days of starvation (day 2, $+126 \%, p<0.001)$. This greatly increased on the next day of starvation (day $3,+241 \%, \mathrm{p}<0.001$ ) On the first day of refeeding, the evoked secretion was not significantly different from that of the previous starved day (day 3 starved). By the second day of refeeding, however, the secretion had decreased significantly compared with the first refeeding day (day $2,-58 \%$, $\mathrm{p}<0.01$ ). This fall in the secretion was continued so that on the third day of refeeding the secretion was not significantly different from that in the fed.

With the ileum, the secretion evoked by bethanechol was significantly increased compared with the fed controls on the second day of starvation (day $2,+42 \%, \mathrm{p}<0.01$ ). A further day 


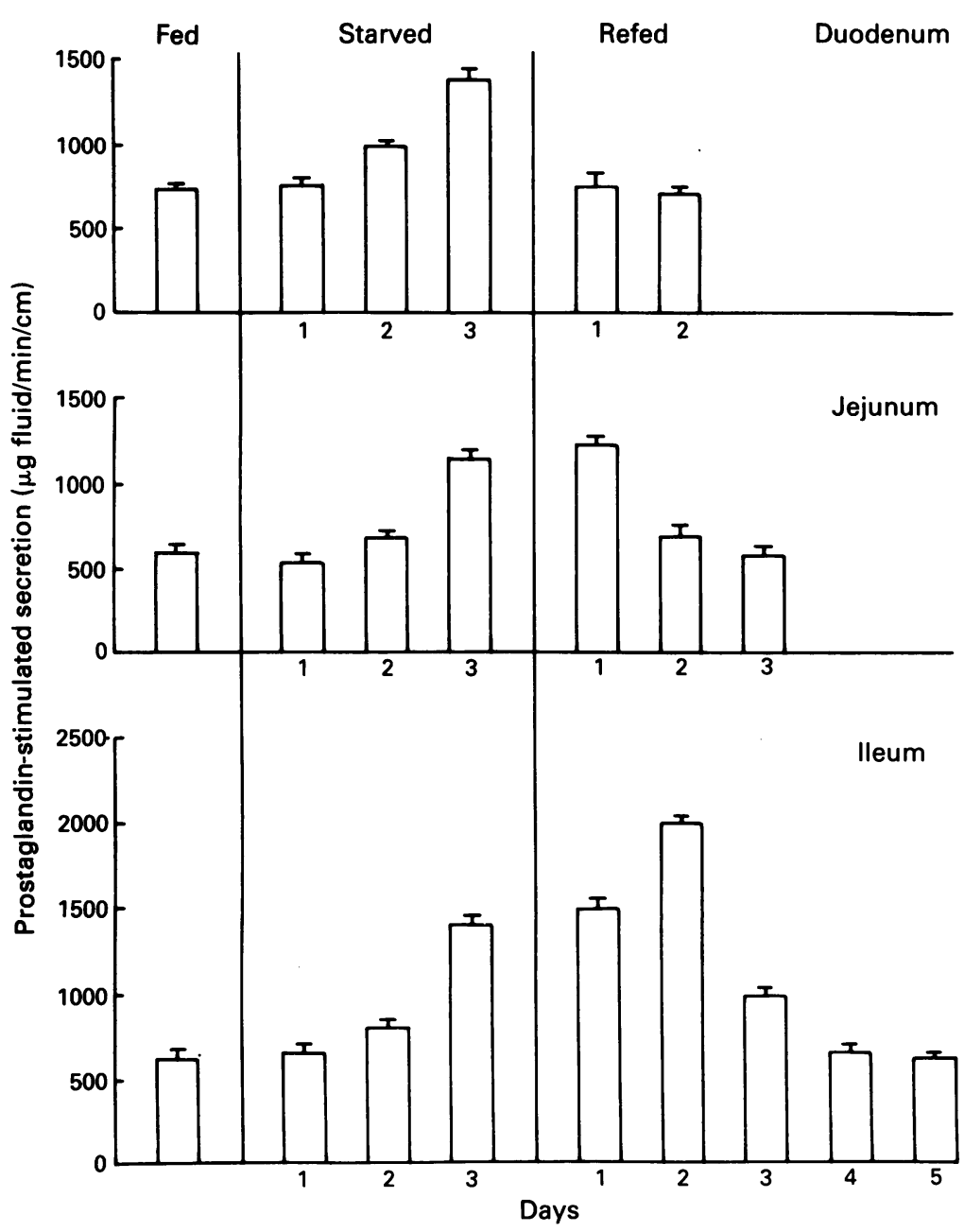

Figure 2: Prostaglandin stimulated fluid secretion ( $\mu$ f fluid/ $\mathrm{min} / \mathrm{cm}$ ) in the duodenum, jejunum, and ileum of fed, 72 hour starved and refed 72 hour starved rats. The results are plotted as mean $(S E)$. The number of animals used varied between six and nine. $P G E_{2}$ was given ip at a dose of $10 \mu \mathrm{g} / \mathrm{kg}$ bwt. See text for details of statistical significance of comparisons by Conover's multiple t test. refeeding, the fluid secretion returned to the fed level $(+10 \%, \mathrm{p}>0.05)$. In the jejunum, $\mathrm{PGE}_{2}$ induced secretion became significantly greater than the fed controls on day $2(+14 \%, \mathrm{p}<0.001)$ and increased further on day $3(+96 \%, \mathrm{p}<0.001)$. It remained at this high level on day 1 of refeeding $(+109 \%, p>0.001)$, decreased slightly on day 2 but still remained significantly higher than the fed level $(+38 \%, \mathrm{p}<0.01)$. By day 3 , however, it had returned to the control values $(-3 \%, \mathrm{p}>0.05)$. In the ileum, $\mathrm{PGE}_{2}$ induced secretion was enhanced on day 2 of starvation $(+295 \%, \mathrm{p}<0.001)$ and increased further on day $3(+126 \%, p<0.001)$. On day 1 of refeeding, the secretion was maintained at the day 3 starved level $(+141 \%, \mathrm{p}<0.001)$ but on day 2 of refeeding it was enhanced more than the starved value $(+222 \%, \mathrm{p}<0.001)$. This fell by day 3 of refeeding $(+60 \%, p<0.001)$ and returned to the fed level by day 4 of refeeding $(+5 \%, p>0.05)$.

\section{E coli STa stimulated fluid movements}

The results for the $E$ coli STa stimulated fluid movements are shown in Figure 3. The pattern for the toxin STa mirrors that for bethanechol and $\mathrm{PGE}_{2}$. In the duodenum, compared with the fed controls, the STa induced secretion was significantly increased on day 2 of starvation $(+115 \%, \mathrm{p}<0.01)$ and it increased further on day $3(+243 \%, p<0.001)$. The secretion returned to the fed level after one day of refeeding $(+10 \%, p>0.05)$. In the jejunum, the STa induced secretion was enhanced on day 2 of starvation $(+64 \%, \mathrm{p}<0.01)$ and was greatly increased by day $3(+160 \%, p<0.01)$. It remained at this high level on day 1 of refeeding $(+162 \%, \mathrm{p}<0.01)$ but was reduced on day 2 of refeeding $(+92 \%, \mathrm{p}<0.001)$ and returned to the fed level on day $3(+9 \%, p>0.05)$. In the ileum, STa induced secretion also showed an enhanced level compared with the fed on day 2 of starvation $(+129 \%, \mathrm{p}<0.001)$ which increased greatly on day $3(+406 \%, p<0.001)$. The STa induced secretion was greater than the previous starved maximum on the first day of refeeding $(+473 \%$, $\mathrm{p}<0.001)$ and reached even higher levels on day 2 of refeeding $(+609 \%, p<0 \cdot 001)$. By day 3 of refeeding, the secretion was decreasing $(+240 \%$, $\mathrm{p}<0.001)$ and was further reduced on day 4 $(+68 \%, p<0.01)$ but it was still greater than the fed level $(p<0.01)$. By day 5 of refeeding, the value had fallen dramatically and the STa induced secretion was not significantly greater than that of the fed ileum $(+10 \%, p>0.05)$.

\section{Discussion}

BASAL FLUID TRANSPORT

The results clearly show that starvation and subsequent refeeding have differential actions on the net basal, unstimulated fluid transport in the duodenum, jejunum, and ileum. When compared with the fed animals, starvation for three days increased duodenal absorption, caused no change in the jejunum but changed the absorptive tone into a net secretory one in the ileum. Refeeding restored duodenal absorption to the fed level within 24 hours but had no influence in duodenum, jejunum and ileum of the fed, starved and refed rats are shown in Figure 2. In the duodenum, $\mathrm{PGE}_{2}$ induced net secretion was not significantly increased above the fed level until 48 hours of starvation $(+42 \%, p<0.001)$. It increased still further on day $3(+99 \%, p<0.001$ compared with fed and $+40 \%, p<0.001$ compared with day 2 starved). After 24 hours of 


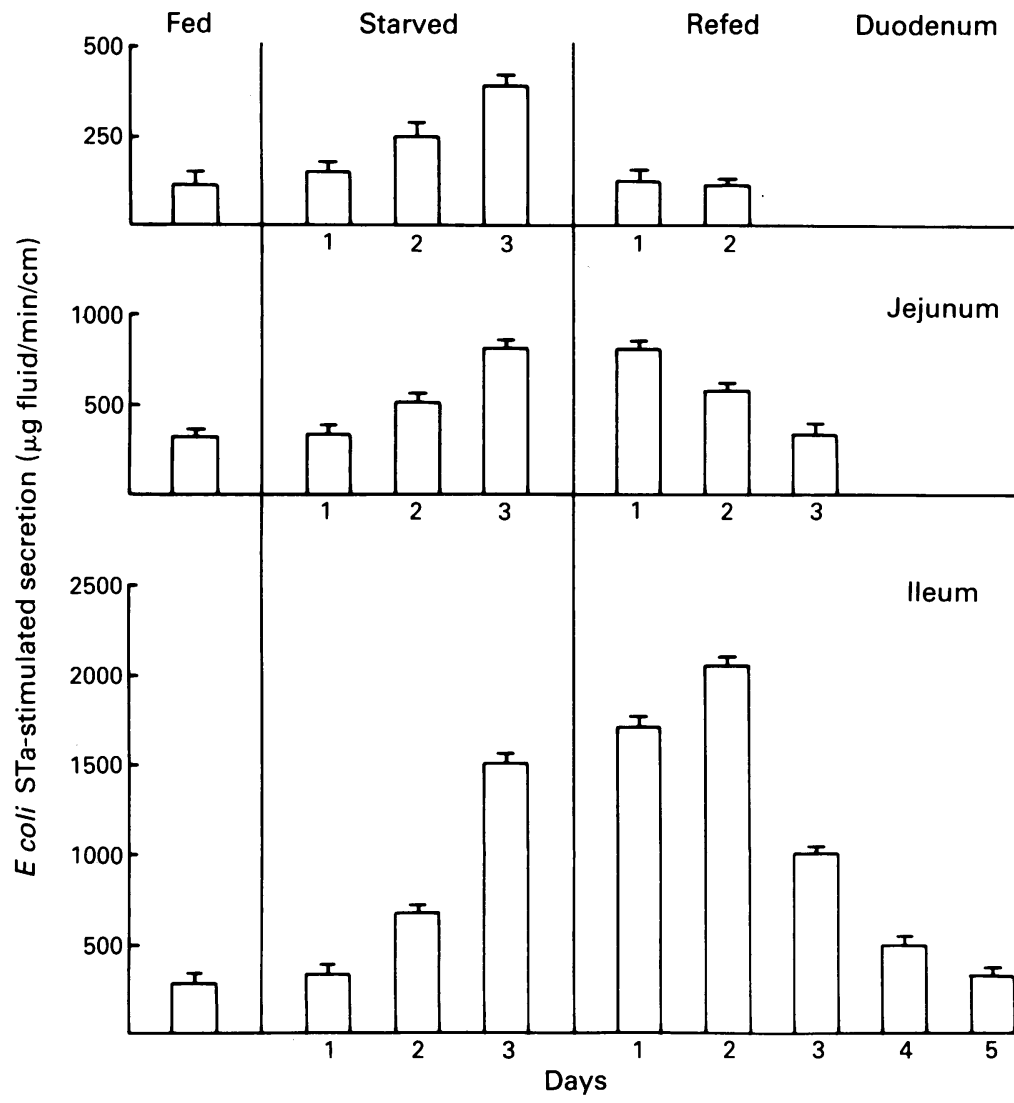

Figure 3: E coli STa stimulated fluid secretion ( $\mu \mathrm{g}$ fluid/min/ $/ \mathrm{cm}$ ) in the duodenum, jejunum, and ileum of fed, 72 hour starved and refed 72 hour starved rats. The results are plotted as mean $(S E)$. The number of animals used varied between six and eight. E coli STa was administered intraluminally at a dose of $500 \mathrm{ng} / \mathrm{ml}$. See text for details of statistical significance of comparisons by Conover's t test. the jejunum. It caused dramatic changes in the ileum, inducing an enhanced secretory tone that was actually greater than the maximum observed during starvation. On continued refeeding this enhanced secretion subsequently subsided and then reversed back to an absorptive tone.

SECRETAGOGUE INDUCED SECRETION

Substantially similar changes were observed, compared with the fed controls in the three regions, in the net fluid secreted in response to bethanechol, $\mathrm{PGE}_{2}$, or $E$ coli STa. In the duodenum, starvation caused increased fluid secretion but only 24 hours of refeeding were needed to restore this to the fed level. In the jejunum, starvation also increased the fluid secretions induced by the secretagogues but 48 hours of refeeding were necessary to restore the secretions to the fed levels. The ileum showed a more complicated picture. While starvation still caused increased secretions, refeeding actually induced further increases in the net fluid secreted on the second day. The secretion induced by $\mathrm{PGE}_{2}$ returned to basal levels after 72 hours of refeeding, that induced by $E$ coli STa and bethanechol took 96 hours to return to normal.

MECHANISMS FOR THE CHANGES

While the results obtained are clear cut they raise a number of questions about the mechanisms that are responsible for the changes observed.
The discussion that follows addresses itself to three major questions: (i) what causes the differential behaviour of the unstimulated duodenum and ileum, but not jejunum during starvation, (ii) what causes the enhanced secretion during starvation in response to secretagogue stimulation in all the regions, and (iii) what causes the differential responses to refeeding in the three areas?

The balance between an absorptive and secretory tone in the small intestine is brought about by a complex interaction of neural and paracrine influences imposed on the basal ion transport functions of villus and crypt cells..$^{20-2+}$ The simple concept that only the crypt enterocytes secrete while the villus cells absorb ${ }^{25}$ has to be modified now as Stewart and Turnberg ${ }^{26}$ have shown that in the rat, $\mathrm{Cl}^{-}$dependent depolarisations occur in the apical membrane potentials of crypt and villus enterocytes when secretion is activated. This strongly suggests that villus cells are involved in secretion as well as absorption. The current explanation for the secretion of fluid by the intestine envisions the fluid moving to the lumen as the osmotic consequence of ion secre$\operatorname{tion}^{27}$ which is often, but not always, electrogenic. ${ }^{28}$ Many of the secretagogues that elicit secretion in vivo also inhibit neutral $\mathrm{NaCl}$ uptake and thus fluid absorption, which obviously appears to amplify the amount of fluid secreted but it is not known if these two processes are always activated simultaneously in vivo. The major ionic component of the basal unstimulated short circuit current measured in vitro in the rat duodenum, jejunum, and ileum has been found to be a lumenally orientated, electrogenic $\mathrm{Cl}^{-}$ secretion with a smaller component of electrogenic $\mathrm{HCO}^{-}$secretion in the duodenum and ileum. ${ }^{10-12}$ In vivo, however, fluid movements linked to the basal electrogenic secretory tone appear to be modulated by neutral, nonelectrogenic absorptive mechanisms in the case of the duodenum but apparently not in the jejunum. Similarly, with the ileum in vivo, the electrogenic secretory mechanisms observed in vitro appear, on the first day of starvation, to be modulated by the neutral absorptive processes. On progressive starvation, however, the absorptive tone becomes dominated by the secretory mechanism(s). It is not unusual to find in vivo and in vitro studies on fluid and ion transfer to be in disagreement. Cooke and Carey, ${ }^{29}$ reviewing the level of enteric tonic neural activity influencing basal ion transfer in vitro (measured as the short circuit current) and basal ion and fluid transfer measured in vivo, reported that the conflicting results were probably caused by factors such as luminal contents and stretch of the gut wall affecting the neural activity at the time of removal or measurement. Thus, although we have shown that secretagogue activated maximum hypersecretory response of the starved small intestine is independent of any neural mechanism in vitro" 11 this does not exclude that in vivo the extrinsic/intrinsic neural innervation of the ileum influences the balance between the basal, net absorptive and secretory tone or the duration of the response.

One fact is clear from the food intake measurements of the starved then refed rats, the changes 
in net fluid movements cannot be the result of differences in food intake as the refed rats intake was not significantly different from fed controls. A possible explanation for refeeding inducing a greater net secretory capacity after one day in the refed compared with the starved ileum, is a 'oneoff rapid migration of immature enterocytes from the base of the villi onto their sides as suggested by Goodlad et $a l^{30}$ from their own studies on the effects of refeeding starved rats. These immature enterocytes would be of the secretory rather than absorptive type, creating an imbalance in the villous cell population which would normalise over the ensuing 24 hours by their maturation on the villus to the absorptive type. Such an explanation, however, is not without its problems. First, why does it only occur in the ileum and not in the duodenum or jejunum? Second, the duodenum is clearly restored to normal secretory function within 24 hours of refeeding yet the ileum takes 72 hours. This rapid restoration upon refeeding is unexpected considering that Goodlad et al ${ }^{30}$ reported that the profoundly depressed crypt cell production rate of the starved duodenum only increased gradually upon refeeding, taking two to three days to return to the fed control level. This suggests that the rapid duodenal secretory response is because of direct changes occurring in the enterocytes actually on the villus rather than through changes in migration or mitosis induced by the feeding. Whatever the final explanation it is clear that the duodenal, jejunal and ileal enterocyte responses to refeeding are different suggesting that the various levels of the small intestine have different operational mechanisms. This conclusion was also offered by Holt, $\mathrm{Wu}$, and $\mathrm{Yeh}^{31}$ who reported that three day starvation in their rat experiments induced hypoplasia in the duodenum but not in the ileum while refeeding caused ileal hypoplasia but restored the duodenum to control levels.

The enhancement of the maximal secretion by starvation in response to bethanechol and $\mathrm{PGE}_{2}$ in all regions of the intestine in vitro is caused by a non-nervous, postreceptor mechanism. ${ }^{1011}$ In the case of $E$ coli STa, however, while the toxin is known to directly activate the production of cyclic GMP in the enterocytes causing both electrogenic ion and fluid secretion ${ }^{32}$ other suggestions are that it can also act, at least in the jejunum, through the enteric neural plexus ${ }^{33}$ to cause fluid secretion or, in a more recent claim, by the local gut release of 5-hydroxytryptamine which then activates ion secretion and inhibits fluid absorption. ${ }^{34}$ Rolfe, Levin, and Young ${ }^{35}$ have shown, however, that the rat ileum even when desensitised to 5-hydroxytryptamine still produces an electrogenic secretory response to mucosal STa and serosal cyclic GMP indicating that at least in vitro, 5-hydroxytryptamine release is not involved in this response. At present the balance between the various proposed mechanisms for STa's action in vivo is not known. Moreover, it may vary in different nutritional states and in different parts of the intestine. This is certainly so in the case of STa's action in the fed rat colon which shows marked differences in the involvement of the enteric nervous system in different segments. ${ }^{36}$
An hypothesis to explain the hypersecretion of starvation in the enterocyte based on published studies has been proposed..$^{37}$ In brief, starvation induces an increase in the level of enterocyte cyclic AMP. ${ }^{39}$ Cyclic AMP is known to be able to induce a selective decrease in the luminal membrane's permeability to $\mathrm{Na}^{+}$ions ${ }^{+0}$ an action that will create an increased transluminal (apical) membrane potential difference in the starved enterocyte. This increased luminal membrane pd has been recorded in starved enterocytes. ${ }^{+1}$ It will enhance the drive on the intracellular $\mathrm{Cl}^{-}$ when the enterocyte is activated to secrete. As starvation causes a chronic rise in glucagon, ${ }^{+2}$ which is itself known to cause a hyperpolarisation of the enterocyte's luminal membrane potential difference, ${ }^{43}$ it is likely that this chronic rise in glucagon is a major cause of the changes induced in the secretory response of the enterocytes during starvation, probably by the increased cyclic AMP level. One additional possibility has been previously alluded to and cannot be discounted is that starvation and subsequent refeeding alters the balance of enterocytes on the villus because of a slower turnover of cells (reduced cell loss and slower mitotic production turnover) which leads to more of the enterocyte population becoming secretory biased than absorptive when compared with population on the fed villus. ${ }^{10}$ Previous studies have suggested, however, that delayed transit up the villus and longer maturation of the enterocytes on the villus predispose the enterocytes to become more absorptive than secretory $\left(\mathrm{Smith}^{44}\right)$. Certainly increase in nutrient absorption by the starved intestine has been documented in previous studies ${ }^{9}$ and more recently shown at an individual enterocyte level by autoradiography. ${ }^{45}$ The enhanced nutrient absorption shown by starved enterocytes is compatible with their enhanced secretion because the nutrients showing enhanced uptake, like amino acids and hexoses, are those transferred by the $\mathrm{Na}^{+}$-cotransporter. ${ }^{945}$ In the starved enterocyte, the hyperpolarisation of the luminal membrane not only enhances the drive on the $\mathrm{Cl}^{-}$ions but also enhances the translocation of the charged $\mathrm{Na}^{+}$nutrient cotransporter. Whether the cyclic AMP levels of refed enterocytes are transiently enhanced above those of the starved thus influencing the secretory functions of the enterocytes is a possible factor that needs to be explored in further studies.

In the context of the food refeeding experiments it is interesting to note that we have examined fluid and electrolyte secretion in starved rats allowed to drink isotonic glucose solution ad lib during the three days of starvation. While the basal net ion transfer (measured as the short circuit current) was unaltered by the simple feeding of glucose it was able to prevent the hypersecretory changes occurring in the jejunum, ${ }^{46}$ partly ameliorated it in the ileum ${ }^{47}$ but not in the colon. ${ }^{47} \mathrm{We}$ do not know if this ameliorating action of glucose is a direct one on the enterocytes by increasing their energy supply or indirect by releasing gut hormones or a mixture of both effects.

Finally, a possible criticism of our descriptive nomenclature of the experimental condition we 
are studying needs comment. While we are measuring 'alimentary induced intestinal fluid hypersecretion' and are equating it with 'alimentary diarrhoea' we have not shown this latter condition in the intact adult rat, although Thaysen and Thaysen ${ }^{7}$ did in young rats. We have detailed previously, however, why the intact, conscious adult rat shows little or no evidence of frank secretory diarrhoea because of the huge reserve capacity of its caecum ${ }^{18}$ to store and reabsorb any excess fluids secreted by the small and large intestine. As the underlying mechanism(s) for any frank, secretory diarrhoea must entail an enhanced secretory component with an unchanged or even reduced absorptive component and as we have shown clearly that in the adult refed starved rat that secretory activity is greatly enhanced even above that of the starved rat in the ileum, we feel justified in naming the hypersecretory condition brought about by the refeeding of the starved rat 'alimentary diarrhoea' rather than the more accurate, but longer and clumsy, 'alimentary induced intestinal hypersecretion.' The refed starved rat model offers exciting possibilities for the exploration of the best nutrients to feed to restore normal absorption and reduce or inhibit the intestinal hypersecretion. AY was supported by a Sheffield University Research Fellowship and RJL recei

1 Helweg-Larsen $\mathrm{P}$, Hoffmeyer $\mathrm{H}$, Kieler J, Thaysen EH Thaysen JH, Thygesen P, Wulff MH. Famine disease in Thaysen JH, Thygesen P, Wulff MH. Famine disease in German concentration camps: complication
Acta Med Scand 1952; 274 (suppl): 1-460.

2 Roediger WEW. Metabolic basis for starvation diarrhoea: implications for treatment. Lancet 1986; i: 1082-4.

3 Hehir P. Effects of chronic starvation during the seige of Kut. $B M \mathcal{F}$ 1922; 1: 865-8.

4 Recht S. Kinderärztliche Erfahrungen nach Belagerungs und Hungerperiode in Budapest. Schweiz Med Wochnschr 1946 76: $563-6$.

5 Heilmeyer L. Hungerschäden. Med Klin 1946; 41: 243-9.

6 James WPT. Effects of protein-calorie malnutrition on intestinal absorption. Ann NY Acad Sci 1971; 176: 244-61.

7 Thaysen EH, Thaysen JH. Morphological changes in the gastro-intestinal tract of the white rat following inanition. gastro-intestinal tract of the white rat followin
Acta Pathol Microbiol Scand 1949; 26: 370-9.

8 Roediger WEW. The starved colon-diminished mucosal nutrition, diminished absorption, and colitis. Dis Colon Rectum 1990; 33: 858-62.

9 Levin RJ. Intestinal adaptation to dietary change as exemplified by dietary restriction studies. In: Batt RM, Lawrence TJ, eds. Function and dysfunction of the small intestine. Liverpool: Liverpool University Press, 1984: 77-93.

10 Young A, Levin RJ. Diarrhoea of famine and malnutrition investigations using a rat model 1 . Jejunal hypersecretion induced by starvation. Gut 1990; 31: 43-53.

11 Young A, Levin RJ. Diarrhoea of famine and malnutrition investigations using a rat model 2 . Ileal hypersecretion induced by starvation. Gut 1990; 31: 162-9.

12 Levin RJ, Young A. Nutritional level and rat proxima duodenal secretion in vitro and in vivo. $\mathcal{f}$ Physiol (Lond) 1988 403: $47 \mathrm{P}$

13 Levin RJ, Nzegwu HC, Young A. Proximal colon secretion in fed and fasted rats. F Physiol (Lond) 1988; 396: 33P

14 Levin RJ, Parker A. Rectal electrogenic secretion - is it a putative indicator of intestinal secretory status induced by nutritional deprivation in the rat? Exp Physiol 1990; 75: 609-11.

15 Young A, Pereira MMC, Warren MA, Levin RJ. Hypersecretion associated with the action of Escherichia coli Sta enterotoxin on the jejunum and ileum from starved and chronically undernourished rats. Med Sci Res 1988; 16 $573-4$.

16 Levin RJ, Young A. Differential changes in electrogenic ion transport associated with progressive starvation and refeedtransport associated with progressive starvation and refeed-
ing in the rat small intestine. $\mathcal{F}$ Physiol (Lond) 1987; 396: ing in $149 \mathrm{P}$.

17 Nzegwu H, Young A, Levin RJ. Effects of starvation and refeeding on electrogenic transport in rat colon: a model for refeeding on electrogenic transport in rat colon: a model

18 Fondacaro JD, Kolpak DC, Burnham DB, McCafferty GP. Cecectomised rat - a model for experimental secretory diarrhea in conscious animals. F Pharmacol Method 1990; 24: $59-71$.

19 Theodorsson-Nordheim E. Kruskal-Wallis test: BASIC computer program to perform nonparametric one-way analysis of variance and multiple comparisons on ranks of several independent samples. Comput Methods Programs Biomed 1986; 23:57-62.

20 Cooke $H$. Role of the 'little brain' in the gut in water and electrolyte homeostasis. Faseb f 1989; 3: 127-38.

21 Lundgren $O$. Nervous control of intestinal transport. In: Grundy D, Read NW, eds. Clin Gastroenterol. London: Balliere Tindall, 1988; 2: 85-106.

22 Hemlin $M$. Interactions between sympathetic fibres and transport in the rat jejunal mucosa in vivo. Acta Physiol Scand 1989; 137: 365-74.

23 Nzegwu H, Levin RJ. An enteric neural muscarinicadrenergic pathway (ENCAP) that inhibits serotonin electrogenic ion secretion in rat proximal, mid and distal colon in vitro. 7 Physiol (Lond) 1990; 430: 18P.

24 Beesley A, Levin RJ 5-Hydroxytryptamine induces electrogenic secretion and simultaneously activates a modulating inhibitory neural circuit in rat small intestine in vitro. Exp Physiol 1991; 76: 607-10.

25 Donowitz M, Welsh M. Regulation of mammalian small intestinal electrolyte secretion. In: Johnson LR, ed. Physiology of the gastrointestinal tract. 2nd ed. New York: Raven Press, 1987: 1351-88.

26 Stewart CP, Turnberg LA. A microelectrode study of responses to secretagogues by epithelial cells on villus and crypt of rat small intestine. Am 7 Physiol 1989; 257: G334-43.

27 Halm DR, Frizzell RA. Intestinal chloride secretion. In: Lebenthal E, Duffey ME, eds. Textbook of secretory diarrhea. New York: Raven Press, 1990: 47-58

28 Beubler E, Coupar IM, Hardcastle J, Hardcastle PT. Stimulatory effects of 5-Hydroxytryptamine on fluid secretion and transmural potential difference in rat small intestine are mediated by different receptor subtypes. $\mathcal{F}$ Pharm are mediated by different

29 Cooke HJ, Carey HV. Neural regulation of intestinal ion transport In: Lebenthal E, Duffey ME, eds. Textbook of secretory diarrhea. New York: Raven Press, 1990: 1-14.

30 Goodlad RA, Plumb JA, Wright NA. Epithelial cell proliferation and intestinal absorptive function during starvation and refeeding in the rat. Clin $S_{c i}$ 1988; 74: 301-6.

31 Holt PR, Wu S, Yeh K-Y. Ileal hyperplastic response to starvation in the rat. Am f Physiol 1986; 251: G12+-31.

32 Jacewicz M, Hull AE, Keusch GT. Enterotoxin receptors. In Lebenthal E, Duffey ME, eds. Textbook of secretory diarrhea. New York: Raven Press, 1990: 139-62.

33 Eklund S, Jodal M, Lundgren $\mathrm{O}$. The enteric nervous system participates in the secretory response to the heat stable enterotoxins of Escherichia Coli in rats and cats. Neuroscience 1985; 14: 673-81.

34 Beubler E, Badhri P, Degen A. Involvement of serotonin $(5-\mathrm{HT})$ in fluid secretion induced by heat-stable enterotoxin of E Coli (ST) [Abstract]. Z Gastroenterol 1990; 28: +15 .

35 Rolfe V, Levin RJ, Young A. Electrogenic secretion in rat intestine in vitro activated by E Coli STa is not mediated by local release of 5-Hydroxytryptamine. $\mathcal{F}$ Physiol (Lond) 1992; 446: 107P

36 Young A, Levin RJ. Segmental heterogeneity of rat electrogenic secretion in response to the bacterial enterotoxin
Escherichia Coli STa in vitro. Exp Physiol 1990; 76: 607-10.

37 Levin RJ. The hypersecretory response of the small intestine a unitary hypothesis [Abstract]. Z Gastroenterol 1990; 28: 428.

38 Levin RJ. The diarrhoea of famine and severe malnutrition - is glucagon the major culprit? Gut 1992; 33: +32-4.

39 Levin RJ, Young A. Cyclic AMP levels stimulated by secretagogues are greater in ileal enterocytes isolated from starved compared to fed rats. F Phvsiol (Lond) $1990 ; 424: 8 \mathrm{P}$.

40 Murer H, Hopfer U, Kinne R. Adenylate cyclase sustem in the enterocyte: cellular localisation and possible relation to transepithelial transport. In: Bonfils S, Fromageot P, Rosselin G, eds. First International Symposium on Hormonal Receptors in Digestive Tract Phy'siolog, INSERM symposium No 3 Amsterdam: Elsevier/North Holland Biomedical Press, 1977: 425-34.

41 Debnam ES, Thompson CS. The effect of fasting on the potential difference across the brushborder membrane of
enterocytes in rat small intestine. F Physiol (Lond) $1985 ; 355$ : enterocy

42 Rudo ND, Lawrence A, Rosenberg TH. Treatment with glucagon-binding antibodies alters intestinal response to starvation in the rat. Gastroenterolog' 1975; 69: 1265-8.

43 Thompson CS, Debnam ES. Hyperglucagonaemia: effects on active nutrient uptake by the rat jejunum. 7 Endocrinol 1986 : 111: $37-42$

44 Smith MW. Expression of digestive and absorptive function in differentiating enterocytes. Ann Rev Physiol 1985: 47: 247-60.

45 Thompson CS, Debnam ES. Starvation-induced changes in the autoradiographic localisation of valine uptake by rat the autoradiographic localisation of valine

46 Young A, Levin RJ. The effects of glucose feeding during starvation on rat jejunal secretion. Proc Nutr Soc 1987; 46: $2+\mathrm{A}$

47 Young A, Nzegwu H, Levin RJ. Glucose feeding during starvation and its effects on secretion in the rat ileum and
colon. Proc Nutr Soc 1988; $47: 1+4$. 